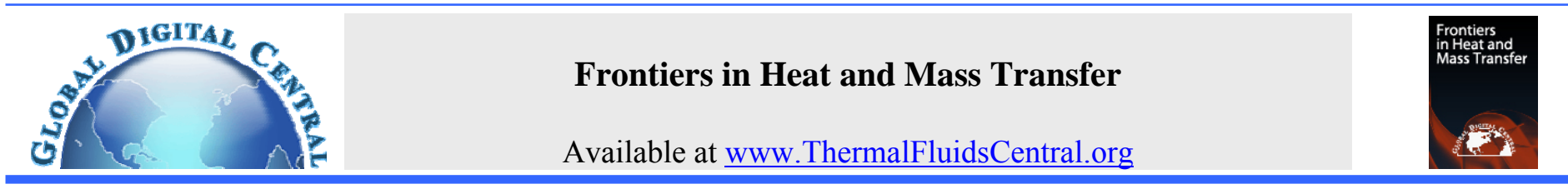

\title{
CONTACT ANGLE MEASUREMENTS FOR ADVANCED THERMAL MANAGEMENT TECHNOLOGIES
}

\author{
Sally M. Smith* Brenton S. Taft ${ }^{\dagger}$ Jacob Moulton \\ Air Force Research Laboratory Space Vehicles Directorate, Kirtland AFB, NM 87117, USA
}

\begin{abstract}
This study investigates the wettability of fluid-solid interactions of interest for oscillating heat pipe (OHP) applications. Measurements were taken using two techniques: the sessile drop method and capillary rise at a vertical plate. Tested surface materials include copper, aluminum, and Teflon PFA. The working fluids tested were water, acetone, R-134a, and HFO-1234yf. A novel low-pressure experimental setup was developed for refrigerant testing. Results show that the refrigerants have significantly lower hysteresis than the water and acetone-based systems, which is thought to lead to better heat transfer in OHP design.
\end{abstract}

Keywords: Wettability, Hysteresis, Interfacial Phenomena, Refrigerants, Oscillating Heat Pipe.

\section{INTRODUCTION}

\subsection{Problem Description}

This study investigates the wettability of fluid-solid interactions for oscillating heat pipe (OHP) applications. Presented here are the methods and procedures for the experiments conducted, and a discussion of the results. Materials studied were substrates of millfinish aluminum (alloy 6061), copper (alloy 101), and Teflon PFA. Working fluids used were distilled water, acetone, R-134a $(1,1,1,2-$ Tetrafluoroethane), and HFO-1234yf (2,3,3,3-Tetrafluoropropene).
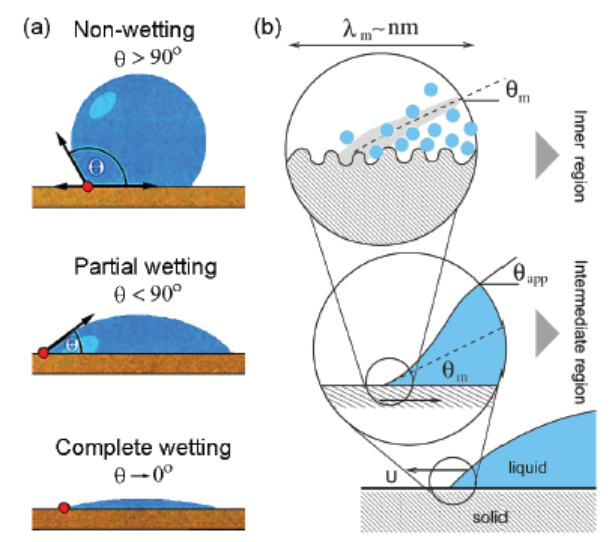

Fig. 1 (a) Contact angle of a fluid on solid substrate. (b) The moving meniscus seen on three different length scales (Khandekar et al., 2010).

\subsection{Relevance of Contact Angle to OHPs}

Contact angle hysteresis is an important parameter in OHP performance. During OHP operation, the advancing and receding contact angles of liquid plugs change with filling ratio, working fluid, capillarity diameter, transfer power, and capillary length. Some results (Taft et al., 2012) have demonstrated that increasing contact angle hysteresis negatively affects the heat transfer of the OHP, while other theories (Qu and $\mathrm{Wu}, 2011)$ suggest a decreasing Young contact angle, $\theta_{0}$, leads to decreased active nucleation site density and deteriorated boiling heat transfer at the evaporator. It is not clear whether contact angle hysteresis or the Young contact angle has greater influence on OHP performance, or if they work collectively to reduce heat transfer. More research is needed before these phenomena can be well understood.

Unfortunately, the dynamic contact angle of varying working fluid/substrate combinations is not possible to estimate, and the database of measured contact angles is nearly an empty set. Dynamic contact angles are, however, worth considering for working fluid/substrate selection if the dynamic contact angle hysteresis is known, or can be measured (Qu et al., 2003).

Table 1 Contact angle and strength of interactions (Khandekar et al., 2010).

\begin{tabular}{|c|c|}
\hline Contact Angle & Degree of Wetting \\
\hline $0^{\circ}$ & Perfect wetting \\
\hline $0^{\circ}<\theta<90^{\circ}$ & High wettability \\
\hline $90^{\circ} \leq \theta<180^{\circ}$ & Low wettability \\
\hline $180^{\circ}$ & Perfectly non-wetting \\
\hline
\end{tabular}

\section{BACKGROUND}

\subsection{Contact Angles}

The contact angle of a fluid-solid interaction characterizes the wettability of a solid surface by a liquid. Liquid with a small contact angle has high wettability, and will spread on the solid surface. The

\footnotetext{
${ }^{*}$ Currently at NASA Wallops Flight Facility, Wallops Island, VA, 23337, USA

† Corresponding author.Email: afrl.rvsv@kirtland.af.mil
} 
contact angle of a liquid on a solid substrate depends on the roughness and the chemical homogeneity of the surface. The three-phase (solid/liquid/vapor) contact line is deformed due to physical and chemical heterogeneities (Zhang et al., 2004).

The surface contact angle, $\theta$, is a generic term that can describe a variety of angles a drop can make with a surface (Tadmor and Yadav, 2008). In this study, we will discuss four contact angles of interest: equilibrium Young contact angle, $\theta_{0}$, the as-placed contact angle, $\theta_{A P}$, the advancing contact angle, $\theta_{A}$, and the receding contact angle, $\theta_{R}$.

\subsection{Young Equilibrium and As-Placed Contact Angles}

The Young angle, $\theta_{0}$, is the equilibrium contact angle of an ideal solid surface. In his original publication, Young (Schwartz, 1980) described static contact equilibrium as a balance of forces at the threephase contact line. The current interpretation of Young's equation (Khandekar et al., 2010; Diaz et al.., 2010; Benner et al., 1982) is of a macroscopic relationship between interfacial tensions

$$
\gamma_{S L}+\gamma_{L G} \cos \left(\theta_{Y}\right)=\gamma_{S G}
$$

where $\gamma_{S L}$ is the interfacial tension between liquid and solid states, $\gamma_{L G}$ is the interfacial tension between liquid and gaseous states, and $\gamma_{S G}$ is the interfacial tension between solid and gaseous states.

The determination of the Young angle is important for characterizing solid-liquid interfacial systems, because it is closely related to material properties (Marmur, 2006). The Young angle represents true thermodynamic equilibrium: mechanical, chemical and thermal. Therefore to satisfy Young's equation, one must have a surface that is chemically homogenous and perfectly smooth (Khandekar et al., 2010). In practice, these requirements mean that the Young angle cannot be directly determined experimentally.

Therefore, in practice, the "static" contact angle of a non-ideal surface is reported as the as-placed contact angle, $\theta_{A P}$, in which a drop of fluid is gently placed on the surface. This angle is highly dependent on the thermophysical properties of the liquid and the vapor, the physico-chemical structure of the solid substrate, and ambient conditions - particularly temperature and humidity (Khandekar et al., 2010). There is experimental evidence that when a sessile drop is placed on a solid surface, the apparent contact angle can vary by several degrees, and often tends toward the advancing contact angle value (Butt et al., 2007).

It has been shown that multiple values of contact angles can be measured on the same surface, even when that surface is smooth and homogenous down to the atomic level (Torrigiani, 2005). This variation in the as-placed contact angle value can be explained by the presence and varying thickness of an adsorbed film that develops next to the triple-phase contact line (Butt et al., 2007). There is a need for careful humidity control, particularly when using water as the liquid phase (Holmes-Farley, 1985). Ambient temperature, relative humidity, vapor pressure, adsorption constants, and evaporation rates all play significant roles in the value of the as-placed contact angle, $\theta_{A P}$ (Diaz et al., 2010). As such, the as-placed angle is non-unique, but is often reported as an auxilary measurement.

\subsection{Hysteresis}

A better method for characterizing a solid surface is to report the maximal advancing, $\theta_{A}$, and minimal receding, $\theta_{R}$, contact angles (Rodriquez-Valverde et al., 2010). This is because $\theta_{A}$ and $\theta_{R}$ are extreme values and are considered means of obtaining thermodynamic properties (Tadmor and Yadav, 2008). These dynamic angles can also be used to estimate the Young angle, $\theta_{0}$, as seen in this analysis and in earlier studies (Della Volpe et al., 2002; Tadmor, 2004). If the contact angle is measured while the volume of the drop is increasing, this is called the advancing angle, $\theta_{A}$, as seen in Fig. 2(a). Practically, this is done just before the three-phase contact line starts to advance.
Similarly, if the angle is measured while the volume is decreasing, this is called the receding angle, $\theta_{R}$, as in Fig. 2(b).
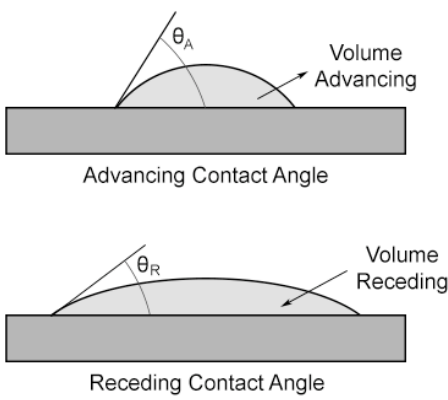

Fig. 2 (a) Advancing contact line and (b) receding contact line of a drop on a horizontal surface.

The difference between the advancing and receding angles is known as the dynamic contact angle hysteresis, $\Delta \theta$. The size of the $\left[\theta_{A}\right.$, $\left.\theta_{R}\right]$ domain is usually attributed to the surface roughness of the solid substrate, and the Young angle lies somewhere within this domain (Van Mourik, 2013). Contact angle hysteresis is useful for characterizing surface roughness, heterogeneity, and mobility.

In addition to surface roughness, hysteresis is also influenced by microscopic chemical heterogeneity, drop size relative to physical topography, molecular reorientation, impurities on the surface, and the penetration of liquid molecules into the solid surfaces (Khandekar et al., 2010; Erbil et al., 1999). These defects change the value of the hysteresis, which is reported as an absolute value. However, the absolute values of the angular deviations of $\theta_{A}$ and $\theta_{R}$ from the Young angle $\theta_{0}$ are typically different, i.e. $\left|\theta_{A}-\theta_{0}\right| \neq\left|\theta_{R}-\theta_{0}\right|$ (Tadmor, 2004). That is to say, the Young angle does not necessarily fall in the center of the contact angle hysteresis.

\subsection{Measurement Techniques}

There is a wide range of techniques used to measure the wettability of a fluid-solid interfacial interaction (Pappas et al.., 2013). Even for simple microscopic examination, equipment can involve a goniometer (Sklodowaka et al., 1999; Gajewski, 2008), tensiometer (Extrand, 2003; Shirtcliffe et al., 2004; Tang et al., 2004), and CCD (charge-couple device) or digital camera (Bernardin et al., 1997; Lamour and Hamraoui, 2010). For experimental setups using separate software analysis, the angle is typically measured using either a custom MATLAB script or by using one of several Java plugins.

The two most frequently reported methods of measuring contact angle through microscopic examination are the sessile drop method and the Wilhelmy plate method, but other common techniques use the mutual displacement of two immiscible fluids through a capillary, the spreading of a liquid between two parallel plates, and rotation of a cylinder partially submerged in liquid, and the capillary rise of a liquid on a partially submerged plate (Dussan, 1979).

The choice of contact angle method depends directly on the geometry of the system. For this study, two techniques were used: the sessile drop method and capillary rise at a flat plate. Because of the physical limitations of the refrigerants of interest, R-134a and HFO$1234 \mathrm{yf}$, the capillary rise method was chosen for ease of integration into a vacuum setup. The sessile drop method was also performed for comparison with the capillary method, as well as an assessment of our experimental set-up using existing literature values.

\subsection{Sessile Drop Method}

To measure the as-placed contact angle, $\theta_{A P}$, a liquid drop is placed on a horizontal solid surface. Fig. 3 demonstrates the basic configuration. In this study, the drop was photographed using a digital camera and measured with separate software analysis. Because drop size can vary between tests, and $\theta_{A P}, \theta_{A}$ and $\theta_{R}$ are functions of drop size (Tadmor 
and Yadav, 2008; Amirfazli et al., 1998; Yekta-Fard and Ponter, 1988; Herzberg and Marian, 1970; Good and Koo, 1979), this process was repeated several times in order to calculate an average.

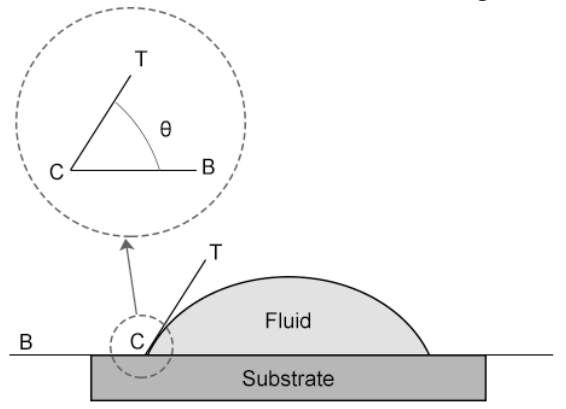

Fig. 3 Sessile drop technique of contact angle measurement. Line $T$ denotes the tangent to a drop's profile at the triple-phase contact point, or point $\mathrm{C}$. Line $\mathrm{B}$ denotes the baseline tangent to the substrate surface. The contact angle $\theta$ is between Line B and Line $\mathrm{T}$ at point $\mathrm{C}$.

The sessile drop method can also be used to measure the advancing and receding contact angles and thus contact angle hysteresis. The dynamic angles can be measured by placing a liquid drop on a horizontal surface and then slowly tilting the surface; the measurement is taken just before the wetting line begins to advance, when the angles of the leading and receding edges provide the advancing and receding angles, respectively. This method has an accuracy of approximately 1 to $5^{\circ}$ (Erbil et al., 1999). However, it has been shown that $\theta_{A}$ and $\theta_{R}$ obtained by tilting the surface are functions of the tilt angle and differ from those of planar surfaces.

A second, more accurate way to obtain the dynamic angles is to use the tip of a needle or fine wire to add or remove liquid from a static sessile drop. As liquid is slowly added to the drop, the angle is repeatedly measured until the maximum advancing angle, $\theta_{A}$, is obtained, or just before the wetting line begins to advance. Similarly, as liquid is removed from the drop, the minimum receding angle, $\theta_{R}$, is obtained just before the wetting line begins to recede. This technique typically has a higher accuracy than the tilting plate approach (Erbil, 1999), and therefore was chosen for this study.

It should be noted that on non-ideal surfaces, wetting lines tend to continuously attach to and detach from the surface, creating an unsteady movement. This causes difficulty in both the measurement and interpretation of the contact angle (Tripathi et al., 2010). To account for this variation, we repeated each individual measurement ten times to acquire an average value.

\subsection{Capillary Rise Method}

For a vertical, flat plate brought into contact with a pool of liquid, the liquid will rise on the plate to a height $h$ (Fig. 4). The height of this capillary rise can be obtained from a straightforward integration of the Laplace equation of capillarity (Budziak and Neumann, 1990), as detailed in Section 3.4.

Although it is not clear if a "static" contact angle can be obtained using this technique, the dynamic contact angles are clearly accessible. The advancing angle, $\theta_{A}$, can be achieved by lowering the vertical plate into the liquid, reducing the height of the capillary rise. Similarly, the receding angle, $\theta_{R}$, can be found by withdrawing the plate from the liquid, raising the height of the capillary rise (Budziak and Neumann, 1990). This technique is illustrated in Fig. 5.

Typically, plate movement is achieved by attaching the plate to a motor-driven mechanism and then raising and lowering the plate into the liquid. However, for this experiment, we used a stationary plate setup and increased or decreased the volume of the liquid to raise or lower the liquid level. That is, by adding liquid we simulated a dropping plate and obtained the advancing contact angle; by removing liquid we simulated a rising plate to find the receding contact angle.

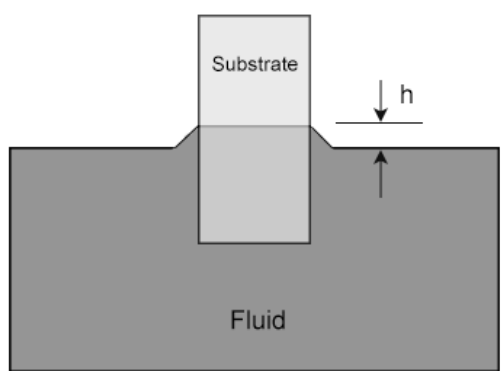

Fig. 4 Schematic of capillary rise at a vertical plate. The height $h$ is the height of the capillary rise.

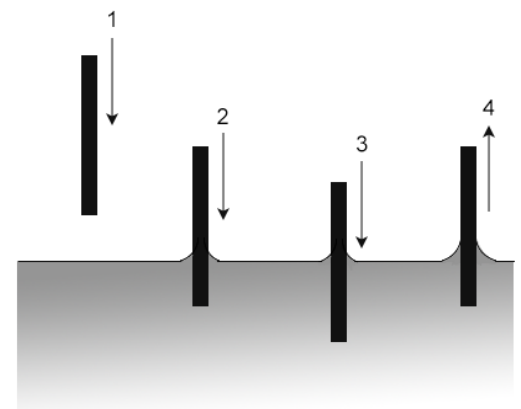

Fig. 5 A submersion cycle: (1) the sample approaches the liquid, (2) the sample is in contact with the liquid surface, (3) the liquid rises up, creating an advancing contact angle, (4) the sample is pulled up, creating a receding contact angle.

\subsection{Literature Values}

Relevant to this experiment is existing data on the interaction of potential working fluids (water, acetone, HFO-1234yf, and R-134a) with various OHP materials (PFA, copper, and aluminum). While there exists a significant amount of data for the interaction of water with the solid materials, the other working fluids have a nearly empty data set.

In the following tables, we report literature values for contact angle measurement with acetone and with R134a. There is no existing data available for either acetone or HFO-1234yf with any of the substrates of interest (PFA, copper, and aluminum). In Table 2, the reported values were measured using the sessile drop technique. In Table 3 , measurements were taken by direct observation of the capillary rise on a vertical plate.

\section{MATERIALS AND METHODS}

\subsection{Test Matrix}

Because this experiment was intended to investigate properties of working fluids and materials for OHP applications, the following materials were chosen for contact angle measurement: substrate materials of mill-finish aluminum (alloy 6061), copper (alloy 101), and Teflon PFA; working fluids of distilled water, acetone (Univar 100\%), DuPont ${ }^{\mathrm{TM}}$ Suva ${ }^{\circledR}$ R-134a (1,1,1,2-Tetrafluoroethane), and Honeywell HFO-1234yf (2,3,3,3-Tetrafluoropropene). Although water is increasingly less popular as an OHP working fluid, it was chosen as a reference liquid for comparison to literature values.

The test matrix, Table 4, details which techniques used both the sessile drop and capillary rise techniques, or only capillary rise, based on physical restrictions of the working fluids (i.e. the refrigerants are not liquid at typical room pressure and temperature). 
Table 2 Literature values for as-placed contact angle $\left(\theta_{A P}\right)$ of water using sessile drop technique.

\begin{tabular}{|c|c|c|c|c|c|c|}
\hline Fluid & Surface & $\begin{array}{c}\text { Temp } \\
\left({ }^{\circ} \mathrm{C}\right)\end{array}$ & Humidity & $\theta_{A P}$ & $\theta_{A}$ & $\theta_{R}$ \\
\hline Water & Teflon PFA (Goswami et al., 2008) & $20-25$ & $70 \% *$ & $110^{0}$ & $110^{0}$ & $95^{0}$ \\
\hline Water & Teflon PFA (Hung et al., 1999) & $N / A$ & $72 \% *$ & $115^{0}$ & $N / A$ & $N / A$ \\
\hline Water & Teflon PFA (Extrand, 2003) & $N / A$ & $N / A$ & $N / A$ & $109^{0}$ & $84^{0}$ \\
\hline Water & Copper 101 (Shoji and Zhang, 1984) & 20 & $71 \% *$ & $71^{0}$ & $92^{0}$ & $48^{0}$ \\
\hline Water & Copper 101 (Yekta-Fard and Ponter, 1985) & 20 & $100 \%$ & $78^{0}$ & $N / A$ & $N / A$ \\
\hline Water & Copper 101 (Extrand, 2003) & $N / A$ & $80 \% *$ & $69^{0}$ & $N / A$ & $N / A$ \\
\hline Water & Copper 101 (Larmour and Hamraoui, 2010) & $20-100$ & $72 \% *$ & $9-74^{0} * *$ & $N / A$ & $N / A$ \\
\hline Water & Copper 101 (Li et al., 2008) & $N / A$ & $65 \% *$ & $74^{0}$ & $N / A$ & $N / A$ \\
\hline Water & Aluminum 6061 (Larmour and Hamraoui, 2010) & $50-150$ & $72 \% *$ & $60-90^{0} * *$ & $N / A$ & $N / A$ \\
\hline Water & Aluminum 6061 (Larmour and Hamraoui, 2010) & $<120$ & $72 \% *$ & $N / A$ & $90^{\circ}$ & $N / A$ \\
\hline Water & Aluminum (unknown alloy) (Extrand, 2003) & $N / A$ & $80 \% *$ & $83^{0}$ & $N / A$ & $N / A$ \\
\hline Water & Aluminum 6061 (Cayabyab et al., 2013) & $N / A$ & $80 \% *$ & $69^{0}$ & $N / A$ & $N / A$ \\
\hline
\end{tabular}

* Assumed relative humidity based on location of test

** Results from tests of varying temperature

Table 3 Literature values for contact angle of R-134a using capillary rise technique

\begin{tabular}{|c|c|c|c|c|}
\hline Fluid & Surface & Temp $\left({ }^{\mathbf{0}} \mathbf{C}\right)$ & Humidity & $\boldsymbol{\theta}$ \\
\hline R-134a & Copper 101 (Vadgama and Harris, 2007) & $20^{\circ}$ & $72 \% *$ & $6.5^{0}$ \\
\hline R-134a & Aluminum 3003 (Vadgama and Harris, 2007) & $20^{0}$ & $72 \% *$ & $8.1^{0}$ \\
\hline
\end{tabular}

Table 4 Test Matrix

\begin{tabular}{|l|l|l|l|l|}
\hline & Water & Acetone & R-134a & HFO-1234yf \\
\hline Aluminum (Alloy 6061) & $\begin{array}{l}\text { Sessile Drop } \\
\text { Capillary Rise }\end{array}$ & $\begin{array}{l}\text { Sessile Drop } \\
\text { Capillary Rise }\end{array}$ & Capillary Rise* & Capillary Rise* \\
\hline Copper (Alloy 101) & $\begin{array}{l}\text { Sessile Drop } \\
\text { Capillary Rise }\end{array}$ & $\begin{array}{l}\text { Sessile Drop } \\
\text { Capillary Rise }\end{array}$ & Capillary Rise* & Capillary Rise* \\
\hline Teflon PFA & $\begin{array}{l}\text { Sessile Drop } \\
\text { Capillary Rise }\end{array}$ & $\begin{array}{l}\text { Sessile Drop } \\
\text { Capillary Rise }\end{array}$ & Capillary Rise* & Capillary Rise* \\
\hline \multicolumn{4}{|c|}{ * performed under vacuum } \\
\hline
\end{tabular}

\subsection{Sessile Drop Procedure}

The experimental facility for the sessile drop technique consisted of a camera-based setup, as seen in Fig. 6. Images were captured using a Canon 30D digital camera with an EFS $60 \mathrm{~mm}$ macro lens $(1: 2.8$ USM). A diffuser was placed between the lamp and the sample to minimize heat input and to provide a uniformly bright background of light.

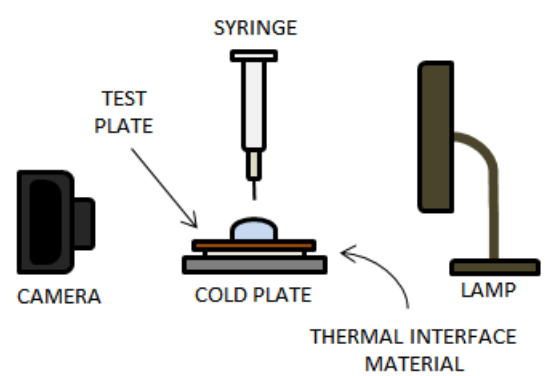

Fig. 6 Experimental setup for sessile drop capture.

The temperature of the solid surface was controlled using a cold plate and thermal pad (Parker Chomerics CHO-THERM 1671), with water circulating through the cold plate at $20^{\circ} \mathrm{C}$. The solid substrate, thermal pad, and cold plate were clamped together to reach the minimum pressure required for the thermal pad to be effective.

Drops were gently placed on the sample using a $30 \mathrm{~mL}$ LuerLok $^{\mathrm{TM}}$ syringe with a $25 \mathrm{G}$ x 1 " Turemo ${ }^{\circledR}$ needle. Drop size was measured to be an average $0.040 \mathrm{~mL}$ for water, and $0.022 \mathrm{~mL}$ for acetone. Between tests, the samples were cleaned with isopropyl and distilled water. This prevented the build-up of residue, particularly from the acetone drops.

For advancing and receding contact angles, liquid was either added or removed from the drop using the syringe and needle. The camera continuously took photos during this process at an average rate of 4.2 photos per second.

\subsection{Capillary Rise Procedure}

The experimental setup for the capillary rise procedure used the same camera and lens as the sessile drop procedure, and included the lamp with diffuser for a high contrast background. However, plate alignment was changed to vertical and the plate was suspended in a clear beaker of fluid, as in Fig. 7. The syringe attached to a stand and a long plastic tube was attached to the syringe needle and then secured to the interior surface of the beaker for stability. This kept fluid movement at the base of the beaker to minimize interference with the fluid surface. Liquid was added to the beaker for an advancing contact angle, and removed from the beaker for a receding contact angle. The camera continuously took photos at a rate of approximately 4.2 photos per second. 
It should be noted that the speed at which the plate moves (i.e. the speed of the contact line) has an effect on dynamic angle measurements. Both the contact line velocity and acceleration influence the dynamic contact angle; in particular, the dynamic contact angle is larger for higher contact line acceleration (Xu et al., 2011). Our speed was chosen based on physical limitations of the camera and syringe system. The resultant average volumetric flow rate of the syringe was 5 $\mathrm{cm}^{3} / \mathrm{s}$, or a surface level change of $0.6 \mathrm{~mm} / \mathrm{s}$.

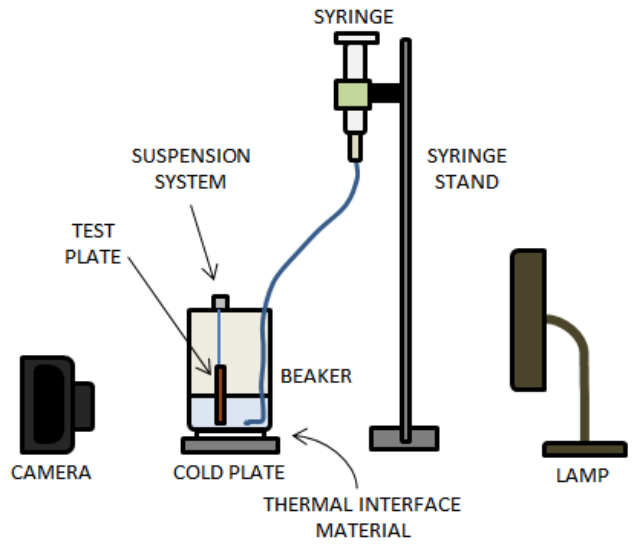

Fig. 7 Experimental setup for capillary rise at a vertical plate under ambient conditions.

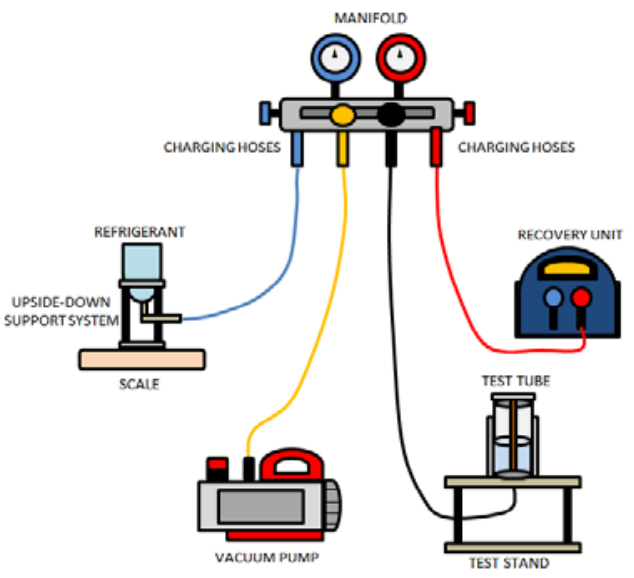

(a) Overall view of experimental setup for capillary rise at a vertical plate under vacuum conditions.

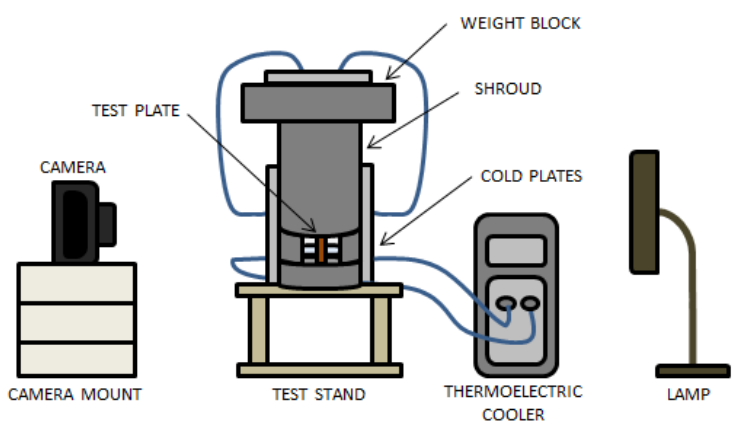

Fig. 8 (b) Test stand detail.

Because the two refrigerants of interest to this study, R-134a and HFO-1234yf, are not liquid at room temperature and pressure, we built a separate system for measuring the dynamic contact angles under vacuum. We constructed a small vacuum apparatus using a clear PETG (polyethylene terephtalate glycol-modified) tube and two custom-built aluminum caps. For safety, an aluminum shroud surrounded the tube, with small viewing windows for light and camera access. Two cold plates were clamped next to the aluminum shroud and connected in series with a NESLAB RTE7 chiller. Water was circulated through this system at $5^{\circ} \mathrm{C}$. The experimental setup is shown in Fig. 8 .

Initially, rough vacuum is pulled on the entire system to a range of approximately 40 to 70 torr. The refrigerant can is tapped, and then opened to fill the test tube. As refrigerant flows into the tube, the internal pressure of the tube rises to arrange of 35 to 50 psi (1810 to 2585 torr). Once a sufficient amount of liquid refrigerant is in the test tube, the manifold lines are closed. After measurements are taken, the recovery unit is used to remove the refrigerant from the test tube, manifold, and the rest of the system.

Because of physical restrictions of the system, raising and lowering the liquid level and/or the plate was not experimentally practical. Thus to find the advancing angle of the fluid/solid interface, the tube was tilted toward the camera, moving the liquid surface higher on the plate on the edge closest to the camera. Similarly, the receding angle was measured by tilting the tube away from the camera, lowering the liquid surface level on the camera side. This replicated the motion of the traditional fluid setup, performed for water and acetone by the capillary rise technique.

\subsection{Analysis}

For the sessile drop technique, the advancing, receding, and as-placed angles were measured using the DropSnake Java plugin, available from the National Institute of health, which applies active contours to an image after the user defines points along the drop outline (Stalder et al., 2010). The raw images were initially post-processed for sharpness and clarity and converted to a black and white format. The DropSnake plugin was chosen over the other ImageJ options (Kwok et al., 1995) because it allows for separate angle measurements of each side of the drop, and because the contour placement method facilitates faster and easier processing.

For the capillary rise technique, the advancing and receding angles captured were measured using a modified form of the Laplace equation. Assuming the vertical plate is sufficiently wide, the Laplace equation (Pogorzelski, et al., 2012) integrates into:

$$
\sin \theta=1-\frac{\Delta \rho g h}{2 \gamma_{L V}}
$$

where $\Delta \rho$ is the difference in density between the fluid and the substrate, $g$ is the acceleration due to gravity, $\gamma_{L G}$ is the liquid-gas surface tension, $h$ is the capillary rise, and $\theta$ is the contact angle. Some fluid/solid systems formed a capillary depression instead of a rise, which created an advancing angle greater than $90^{\circ}$. For these cases, a modified Laplace equation was used that subtracted the angle from $180^{\circ}$.

For both methods, the equilibrium Young contact angle, $\theta_{0}$, was calculated from the advancing and receding angles using Tadmor's equation (2004):

$$
\theta_{0}=\arccos \left(\frac{\Gamma_{A} \cos \left(\theta_{A}\right)+\Gamma_{R} \cos \left(\theta_{R}\right)}{\Gamma_{A}+\Gamma_{R}}\right)
$$

where

$$
\Gamma_{R}=\left(\frac{\sin ^{3} \theta_{R}}{\left(2-3 \cos \theta_{R}+\cos ^{3} \theta_{R}\right)}\right)^{1 / 3}
$$




$$
\Gamma_{A}=\left(\frac{\sin ^{3} \theta_{A}}{2-3 \cos \theta_{A}+\cos ^{3} \theta_{A}}\right)^{1 / 3}
$$

\section{RESULTS}

Table 5 reports the contact angles obtained through the sessile drop technique. The receding, advancing, and as-placed angles were captured in images and processed through software. The Young's equilibrium angle was determined using Tadmor's equation (Eq. 2). Each case was repeated at least ten times to obtain an average value. The standard deviation is included in the table.

As noted earlier, wetting is affected by a large number of factors not only liquid properties but also substrate properties and system conditions. (Lewis, 2006; Kumar and Prabhu, 2007). For this reason, we report the temperature and relative humidity for each system during testing. Laboratory conditions varied across different days, so the table indicates the conditions for each system.

Measurements were not attainable for acetone-aluminum and acetone-copper systems because the angle was too small to measure with the available equipment. Thus, the Young's equilibrium angle, $\theta_{0}$, could not be calculated for these systems.

Table 6 reports the contact angles obtained through capillary rise at a vertical plate. The receding and advancing angles were determined using the height of the capillary rise and Eq. 1. The Young's equilibrium angle was calculated from Tadmor's equation (Eq. 2). Each measurement was repeated at least ten times to obtain a value, and standard deviation is included in the table.

Figure 9 presents results for the sessile drop technique (traditional fluids) and makes a comparison to some available literature values. The water-based systems correlate relatively well with previous research. Published values for acetone-based systems were not available, but our results matched the predicted trend, based on related research, of a contact angle lower than in water-based systems. These results are reported in Table 5, and literature values are summarized in Table 2.

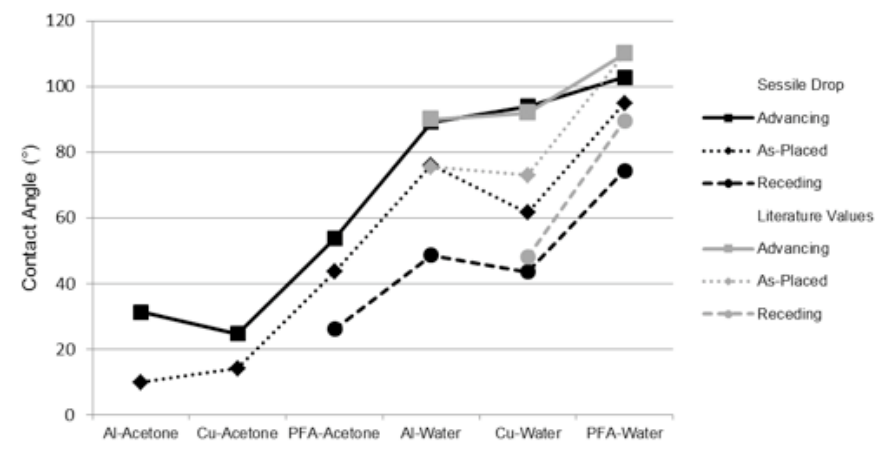

Fig. 9 Contact angle measurements of water and acetone using sessile drop technique.

Figure 10 presents the results for both the sessile drop technique and the capillary rise technique. The figure includes both traditional fluids (water, acetone) and refrigerants (R-134a, HFO-1234yf). The sessile drop technique was performed only for the traditional fluids because of physical limitations of the refrigerants, while the capillary rise technique was used on all four fluids. It should be noted that the capillary rise measurements employed different experimental setups for the refrigerants and the traditional fluids. These results are reported in Table 5 and Table 6.

Figure 11 summarizes the measured dynamic contact angle hysteresis values, or the absolute value of the difference between the advancing contact angle, $\theta_{A}$, and the receding contact angle, $\theta_{R}$. The figure includes results for all four working fluids, and compares the results from the sessile drop technique and the capillary rise technique.

Table 5 Results and standard deviation of experimental advancing, receding and as-placed angles, and calculated Young's equilibrium angle, using the sessile drop technique. Tests were performed under the following atmospheric conditions: ${ }^{1} 19^{\circ} \mathrm{C}$ and $33 \%$ humidity; ${ }^{2} 22{ }^{\circ} \mathrm{C}$ and $21 \%$ humidity; ${ }^{3} 22^{\circ} \mathrm{C}$ and $45 \%$ humidity; ${ }^{4} 22^{\circ} \mathrm{C}$ and $18 \%$ humidity; ${ }^{5} 23^{\circ} \mathrm{C}$ and $32 \%$ humidity; ${ }^{6} 19^{\circ} \mathrm{C}$ and $41 \%$ humidity.

\begin{tabular}{lccc|c}
\hline System & $\theta_{R}\left(^{\circ}\right)$ & $\theta_{A P}\left(^{\circ}\right)$ & $\theta_{A}\left(^{\circ}\right)$ & $\theta_{0}\left(^{\circ}\right)$ \\
\hline Water-Aluminum & $48.68 \pm 1.2^{1}$ & $76.08 \pm 2.3^{1}$ & $89.15 \pm 3.4^{1}$ & 67.02 \\
Water-Copper & $43.50 \pm 3.6^{2}$ & $61.50 \pm 3.7^{4}$ & $93.98 \pm 2.7^{2}$ & 65.78 \\
Water-PFA & $74.39 \pm 3.2^{2}$ & $94.86 \pm 1.9^{4}$ & $102.84 \pm 4.0^{2}$ & 86.91 \\
& & & & \\
Acetone-Aluminum & $N / A$ & $9.93 \pm 1.1^{1}$ & $31.30 \pm 1.5^{1}$ & $N / A$ \\
Acetone-Copper & $N / A$ & $14.18 \pm 3.0^{5}$ & $24.71 \pm 3.6^{2}$ & $N / A$ \\
Acetone-PFA & $26.08 \pm 3.6^{3}$ & $43.50 \pm 1.2^{6}$ & $53.75 \pm 2.8^{3}$ & 38.98 \\
\hline
\end{tabular}

Table 6 Results and standard deviation of experimental advancing, receding and as-placed angles, and calculated Young's equilibrium angle, using the capillary rise at a vertical plate technique. Tests were performed under the following atmospheric conditions: ${ }^{1} 19^{\circ} \mathrm{C}$ and $33 \%$ humidity; ${ }^{2}$ $22^{\circ} \mathrm{C}$ and $21 \%$ humidity; ${ }^{3} 20^{\circ} \mathrm{C}$ and $34 \%$ humidity; ${ }^{4} 21^{\circ} \mathrm{C}$ and $54 \%$ humidity; ${ }^{5} 21^{\circ} \mathrm{C}$ and $58 \%$ humidity; ${ }^{6} 21^{\circ} \mathrm{C}$ and $55 \%$ humidity.

\begin{tabular}{lcc|c}
\hline System & $\theta_{R}\left(^{\circ}\right)$ & $\theta_{A}\left(^{\circ}\right)$ & $\theta_{0}\left(^{\circ}\right)$ \\
\hline Water-Aluminum & $46.99 \pm 1.4^{1}$ & $99.33 \pm 2.9^{1}$ & 69.44 \\
Water-Copper & $53.24 \pm 2.6^{2}$ & $94.14 \pm 0.7^{2}$ & 71.40 \\
Water-PFA & $76.08 \pm 2.6^{2}$ & $94.15 \pm 0.9^{2}$ & 84.49 \\
& & & \\
Acetone-Aluminum & $70.47 \pm 1.4^{3}$ & $73.56 \pm 1.6^{3}$ & 79.16 \\
Acetone-Copper & $77.37 \pm 0.8^{2}$ & $80.99 \pm 1.3^{2}$ & 72.00 \\
Acetone-PFA & $83.78 \pm 1.3^{2}$ & $85.52 \pm 0.6^{2}$ & 84.64 \\
& & & \\
R134a-Aluminum & $60.11 \pm 1.7^{4}$ & $60.88 \pm 1.4^{4}$ & 60.50 \\
R134a-Copper & $58.92 \pm 1.2^{5}$ & $59.58 \pm 1.7^{5}$ & 59.25 \\
R134a-PFA & $53.23 \pm 0.9^{5}$ & $62.16 \pm 2.7^{5}$ & 52.86 \\
& & & \\
HFO1234yf-Copper & $62.16 \pm 2.2^{6}$ & $64.22 \pm 1.1^{6}$ & 63.19 \\
\hline
\end{tabular}


It can be seen from Fig. 9 that, within the sessile drop technique, the acetone-based systems had lower contact angles and lower dynamic contact angle hysteresis than the water-based systems. This is confirmed by the capillary rise technique results (Fig. 10) for water and acetone-based systems. This will likely impact OHP design, although further study is needed to determine the influence of hysteresis on heat transfer performance.

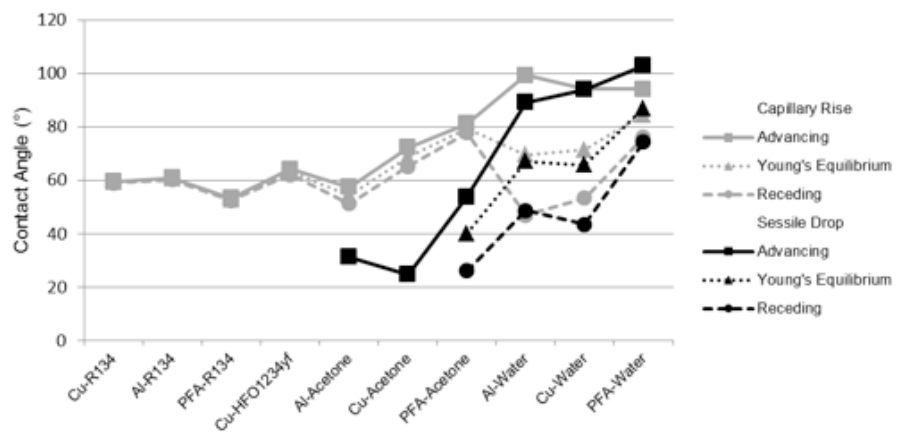

Fig. 10 Contact angle measurements of water, acetone, R-134a, and HFO-1234yf using capillary rise and sessile drop techniques.

Figure 10 demonstrates that the two techniques produce variations in contact angles, in particular for the acetone-based systems. It was noticed that advancing and receding angles obtained through capillary rise at a vertical plate, regardless of the fluid/solid system, are systematically greater than those obtained by the sessile drop technique. This reinforces the notion that a contact angle value is highly dependent on the physical conditions in which it is measured, among other factors. Therefore data comparison must use a relative ranking with consistent procedures and conditions. However, within data from the capillary rise technique, the refrigerants (R-134a and HFO-1234yf) exhibited the lowest dynamic contact angle hysteresis.

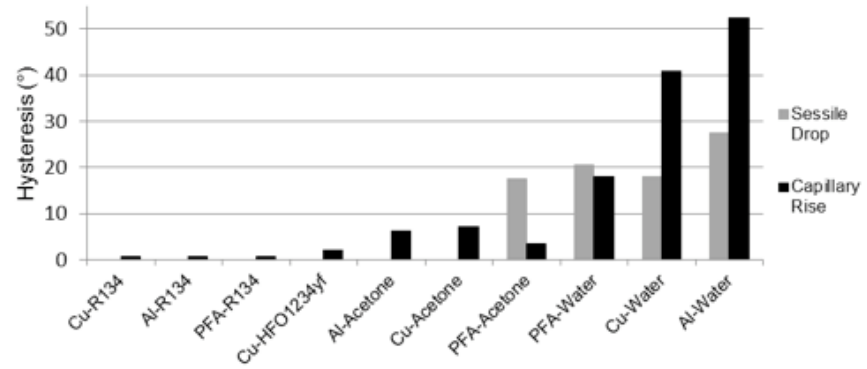

Fig. 11 Measured contact angle hysteresis of water, acetone, R-134a, and HFO-1234yf using sessile drop and capillary rise techniques.

We also noted that the low humidity conditions produced a smaller contact angle, i.e. larger drop radius, than the literature values. This is evident from comparing our sessile drop technique results with literature values (Fig. 9), where the literature values were generally measured in higher humidity environments (Table 2, 3). This corresponds to similar results that show the equilibrium fraction relative humidity increasing with decreasing drop radius (Lewis, 2006).

Not presented with the results is the study performed on an R134a-copper system (Vadgama et al., 2007), reported in Table 3. The reported angle was $6.5^{\circ}$, which is significantly lower than our results. This study included little information on the type of angle measured and conditions for measurement (e.g. relative humidity, temperature, pressure), so therefore a direct comparison cannot be made. Also, the analysis process used by the Vadgama et al. (2007) was a combination of visual observation and a polynomial fitting approach, in which the shape of the meniscus was estimated directly by drawing a tangent to this polynomial at the intersection of the surface and the edge of the drop, i.e. at the three-phase contact line. However, when we applied this technique to our acetone-based systems, we found that it significantly underestimated the advancing and receding angles when compared to our sessile drop technique measurements. Thus we decided that using the Laplace equation (Eq. 2) for analysis was a better choice because it more accurately captured the physical behavior of the system based on work done by Pogorzelski et al. (2012).

\section{CONCLUSIONS}

This study investigated the wettability of fluid-solid interactions for advanced heat transfer applications. Measurements were taken using two techniques: the sessile drop method and capillary rise at a vertical plate. The tested surface materials were copper, aluminum, and Teflon PFA. The working fluids tested were traditional fluids, water and acetone, and refrigerants, R-134a and HFO-1234yf. A novel lowpressure experimental setup was developed for refrigerant testing. Results show that the refrigerants have significantly lower hysteresis than the water and acetone-based systems, which is thought to lead to better heat transfer in an OHP design. This data contributes to the nearly empty set of dynamic contact angle data for the substrates and working fluids of interest.

To complete this data set, further study should be performed on the refrigerants to determine contact angle values with HFO-1234yf with the two additional substrates of interest, PFA and aluminum. A study of the two traditional fluids using the refrigerants' vacuum system for capillary rise technique would allow us to draw a more accurate comparison between traditional and non-traditional fluids.

Further testing and comparison of refrigerant-filled OHPs will be useful for comparing wettability data and OHP performance. The correlation between dynamic contact angle hysteresis and OHP performance is not yet known, and more research is needed before this phenomenon can be well understood.

\section{ACKNOWLEDGEMENTS}

This research was supported by the Air Force Office of Scientific Research, and the Universities Space Research Association. The authors would also like to thank Dr. Derek Hengeveld and Julio Alvarado for their advice and assistance in designing and running the system for capillary rise of the refrigerants.

\section{NOMENCLATURE}

$g \quad$ Acceleration Due to Gravity $\left(\mathrm{m} / \mathrm{s}^{2}\right)$

$h \quad$ Capillary Rise (m)

\section{Greek Symbols}

$\gamma \quad$ Interfacial Tension $(\mathrm{N} / \mathrm{m})$

$\Delta \quad$ Hysteresis, Difference

$\theta \quad$ Contact Angle (degrees)

$\rho \quad$ Density $\left(\mathrm{kg} / \mathrm{m}^{3}\right)$

Subscripts

$0 \quad$ Young's Equilibrium

A Advancing

$A P \quad$ As Placed

$R \quad$ Receding

$S L \quad$ Solid to Liquid States

$L G \quad$ Liquid to Gaseous States

$S G \quad$ Solid to Gaseous States

\section{REFERENCES}

Amirfazli, A., Kwok, D.Y., Gaydos, J., 1998, A.W. Neumann. "Line tension measurements through drop size dependent of contact angle." Journal of Colloid Interface Science, 205, pg. 1-11. http://dx.doi.org/10.1006/jcis.1998.5562 
Benner, R.E., Scriven, L.E., Davis, H.T., 1982, "Structure and stress in the gas-liquid-solid contact region." Faraday Symposia of the Chemical Society. Vol. 16, Royal Society London, pp. 169.

Bernardin, J.D., Mudawar, I., Walsh, C.B., Franses, E.I., 1997, "Contact Angle Temperature Dependence for Water Droplets on Practical Aluminum Surfaces," International Journal of Heat and Mass Transfer, 40(5), pp. 1017-1033. http://dx.doi.org/10.1016/0017-9310(96)00184-6

Budziak, C.J., Neumann, A.W., 1990, "Automation of the Capillary Rise Technique for Measuring Contact Angles," Colloids and Interfaces, 43, pp. 279-293.

Butt, H.J., Golovko, D.S., Bonaccurso, E., 2007, "On the derivation of Young's equation for sessile drops: Nonequilibrium effects due to evaporation." Journal of Physical Chemistry B, 111, pp. 5277. http://dx.doi.org/10.1021/jp065348g

Cayabyab, J., Cu, J.R.L., Leron, A.M.S., 2006, "Contact Angle Measurements," University of the Philippines Diliman. URL: http://www.scribd.com/doc/131275900/06-Contact-Angle-

Measurements [cited 20 June 2013]

Della Volpe, C., Maniglio, D., Morra M., Siboni, S., 2002, "The determination of a 'stable-equilibrium' contact angle on heterogeneous and rough surfaces," Colloids and Surfaces A: Physicochemical and Engineering Aspects, 206, pp. 47. http://dx.doi.org/10.1016/S0927-7757(02)00072-9

Diaz, M.E., Fuentes, J., Cerro, R.L., Savage, M.D., 2010, "Hysteresis during contact angle measurement," Journal of Colloid and Interface Science, 343, pp. 574-583

http://dx.doi.org/10.1016/j.jcis.2009.11.055

Dussan, E. B., 1979, "On the spreading of liquids on solid surfaces: static and dynamic contact lines." Annual Review of Fluid Mechanics. 11, pp. 371-400.

http://dx.doi.org/10.1146/annurev.fl.11.010179.002103

Erbil, H.Y., Mc Hale, G., Rowan, S.M., Newton, M.I., 1999, "Determination of the receding contact angle of sessile drops on polymer surfaces by evaporation," Langmuir, 15, pp. 7378-7385. http://dx.doi.org/10.1021/la9900831

Extrand, C.W., 2003, "Contact Angles and Hysteresis on Surfaces with Chemically Heterogeneous Islands," Langmuir, 19, pp. 3793-3796. http://dx.doi.org/10.1021/la0268350

Gajewski, A., 2008, "Contact Angle and Sessile Drop Diameter Hysteresis on Metal Surfaces," International Journal of Heat and Mass Transfer, 51(19-20), pp. 4628-46 http://dx.doi.org/10.1016/j.ijheatmasstransfer.2008.01.027

Good, R.J., Koo, M.N., 1979, "The effect of drop size on contact angle." Journal of Colloid and Interface Science, 71, pp. 283-292. http://dx.doi.org/10.1016/0021-9797(79)90239-X

Goswami, S., Klaus, S., Benziger, J., 2008, "Wetting and Absorption of Water Drops on Nafion Films." American Chemical Society, 24, pp. $8627-8633$.

Herzberg, W.J., Marian, J.E., 1970, "Relationship between contact angle and drop size." Journal of Colloid and Interface Science, 33, pp. 161-163.

http://dx.doi.org/10.1016/0021-9797(70)90083-4
Holmes-Farley, S.R., Reamey, R.H., McCarthy, T.J., Deutch, J., Whitesides, G.M., 1985, "Acid-based behavior of carboxylic acid groups covalently attached at the surface of polyethylene: the usefulness of contact angle in following the ionization of surface functionality." Langmuir, 1, pp. 725. http://dx.doi.org/10.1021/la00066a016

Hung, M., Resnick, P.R., Smart, B.E., Buck, W.H., 1999, "Fluorinated Plastics, Amorphous." Concise Polymeric Materials Encyclopedia, pp. 499-501.

Khandekar, S., Panigrahi, P.K., Lefevre, F., Bonjour, J., 2010, "Local Hydrodynamics of Flow in a Pulsating Heat Pipe: A Review," Frontiers in Heat Pipes, 1, 023003. http://dx.doi.org/10.5098/fhp.v1.2.3003

Kumar, G., Narayan Prabhu, K., 2007, "Review of non-reactive and reactive wetting of liquids on surfaces," Advances in Colloid and Interface Science, 133, pp. 61-89.

http://dx.doi.org/10.1016/j.cis.2007.04.009

Kwok, D.Y., Budziak, C.J., Neumann, A.W., 1995, "Measurements of Static and Low Rate Dynamic Contact Angles by Means of an Automated Capillary Rise Technique," Journal of Colloids and Interface Science, 173, pp. 143-150.

http://dx.doi.org/10.1006/jcis.1995.1307

Lamour, G., Hamraoui, A., 2010, "Contact Angle Measurements Using a Simplified Experimental Setup," Journal of Chemical Education, 87(12), pp. 1403-1407.

http://dx.doi.org/10.1021/ed100468u

Lewis, E.R., 2006, "The effect of surface tension (Kelvin effect) on the equilibrium radius of a hygroscopic aqueous aerosol particle," Journal of Aerosol Science, 37, pp. 1605-1617. http://dx.doi.org/10.1016/j.jaerosci.2006.04.001

Li, G., Wang, B., Liu, Y., Tan, T., Song, X., Li, E., et al., 2008, "Stable Superhydrophobic Surface: fabrication of interstitial cottonlike structure of copper nanocrystals by magnetron sputtering," Science and Technology of Advanced Materials, 9, pp. 1-6. http://dx.doi.org/10.1088/1468-6996/9/2/025006

Marmur. A., 2006, "Soft contact: measurement and interpretation of contact angles," Soft Matte, 2 (1), pp. 12-17.

http://dx.doi.org/10.1039/b514811c

Pappas, D., Copeland, C., Jensen, R., 2007, "Wettability Tests of Polymer Films and Fabrics and Determination of Their Surface Energy by Contact-Angle Methods", Army Research Laboratory, ARL-TR4052, March 2007, URL: http://www.dtic.mil/cgibin/GetTRDoc?AD=ADA466437 [cited 1 August 2013]

Pogorzelski, S.J., Berezowski, Z., Rochowski, P., Szurkowski, J., 2012, "A novel methodology based on contact angle hysteresis approach for surface changes monitoring in model PMMA-Corega Tabs system," Applied Surface Science, 258, pp. 3652-2658.

http://dx.doi.org/10.1016/j.apsusc.2011.11.132

Qu, J., Wu, H., 2011, "Thermal Performance Comparison of Oscillating Heat Pipes with SiO2/water and Al2O3/water Nanofluids," International Journal of Thermal Sciences, 50(10), pp.1954-1962. http://dx.doi.org/10.1016/j.ijthermalsci.2011.04.004

Qu, W., Fan, C., Ma, T., 2003, "Contact angle hysteresis and capillary resistance of pulsating heat pipe," Journal of Engineering Thermophysics. 
Rodriguez-Valverde, M.A., Montes Ruiz-Cabello, F.J., Gea-Jodar, P.M., Kamusewitz, H., Cabrerizo-Vilchez, M.A., 2010, "A new model to estimate the Young contact angle from contact angle hysteresis measurements," Colloids and Surfaces A: Physicochemical and Engineering Aspects, 265, pp. 21-27.

http://dx.doi.org/10.1016/j.colsurfa.2010.01.055

Schwartz, A., 1980, "Contact angle hysteresis: a molecular interpretation," Journal of Colloid and Interface Science, 75, pp. 404. http://dx.doi.org/10.1016/0021-9797(80)90465-8

Shirtcliffe, N.J., McHale, G., Newton, M.I., Chabrol, G., Perry, C.C., 2004, "Dual-Scale Roughness Produces Unusually Water-Repellent Surfaces," Advanced Materials, 16(21), pp. 1929-1932.

http://dx.doi.org/10.1002/adma.200400315

Shoji, M., Zhang. X.Y., 1984, "Study of Contact Angle Hysteresis (In Relation to Boiling Surface Wettability)." Japanese Society of Mechanical Engineers International Journal, 37(3), pp. 560-567.

Sklodowaka, A., Wozniak, M., Matlakowska, R., 1999, "The Method of Contact Angle Measurements and Estimation of Work of Adhesion in Bioleaching of Metals," Biological Procedures Online, 1, pp. 114-121. http://dx.doi.org/10.1251/bpo14

Stalder, A.F., Melchior, T., Muller, M., Sage, D., Blu, T., Unser, M., 2010, "Low-bond axisymmetric drop shape analysis for surface tension and contact angle measurements of sessile drops," Colloids and Surfaces A: Physicochem. Eng. Aspects, 364, pp. 72-81.

http://dx.doi.org/10.1016/j.colsurfa.2010.04.040

Tadmor, R., 2004, "Line Energy and the Relation between Advancing, Receding, and Young Contact Angles," Langmuir, 20, pp. 7659-7664. http://dx.doi.org/10.1021/la049410h

Tadmor, R., Yadav, P.S., 2008, "As-placed contact angles for sessile drops," Journal of Colloid and Interface Science, 317, pp. 241-246. http://dx.doi.org/10.1016/j.jcis.2007.09.029

Taft, B.S., Williams, A.D., Drolen, B.L., 2012, "Review of Pulsating Heat Pipe Working Fluid Selection," Journal of Thermophysics and Heat Transfer, 26(4), pp. 651-656. http://dx.doi.org/10.2514/1.T3768
Tang, Z.G., Black, R.A., Curran, J.M., Hunt, J.A., Rhodes, N.P., Williams, D.F., 2004, "Surface Properties and Biocompatibility of Solvent-cast Poly[e-caprolactone] Films," Biomaterials, 25, pp. 47414748 .

http://dx.doi.org/10.1016/j.biomaterials.2003.12.003

Torrigiani, M., 2005, "Wetting in the presence of Langmuir Films," MS Thesis, University of Alabama in Huntsville.

Tripathi, A., Khandekar, S., Panigraphi, P.K., 2010, "Oscillatory Contact Line Motion Inside Capillaries," 15th International Heat Pipe Conference, April 25-30, Clemson, USA.

Vadgama, B., Harris, D.K., 2007, "Measurements of the contact angle between R134a and both aluminum and copper surfaces," Environmental Thermal and Fluid Science. 31(8), pp. 979-984. http://dx.doi.org/10.1016/j.expthermflusci.2006.10.010

Van Mourik, S., 2002, "Numerical Modeling of the Dynamic Contact Angle," MS Thesis, University of Groningen, Department of Mathematics, URL: http://www.math.rug.nl/ veldman/Scripties/ VanMourik-afstudeerverslag.pdf [cited 1 August 2013]

Xu, S.H., Wang, C.X., Sun, Z.W., Hu, W.R., 2011, "The influence of contact line velocity and acceleration on the dynamic contact angle: An experimental study in microgravity," International Journal of Heat and Mass Transfer, 54, pp. 2222-2225.

http://dx.doi.org/10.1016/j.ijheatmasstransfer.2011.01.018

Yekta-Fard, M., Ponter, A., 1985, "Surface Treatment and its Influence on Contact Angles of Water Drops Residing on Teflon and Copper," The Journal of Adhesion, 18, pp. 197-206. http://dx.doi.org/10.1080/00218468508079683

Yekta-Fard, M., Ponter, A.B., 1988, "The influences of vapor environment and temperature on the contact angle-drop size relationship," Journal of Colloid and Interface Science, 126, pp. 134140.

http://dx.doi.org/10.1016/0021-9797(88)90107-5

Zhang, J., Li, J., Han, Y., 2004, "Superhydrophobic PTFE Surfaces by Extension," Macromolecular Rapid Communications, 25, pp. 11051108 .

http://dx.doi.org/10.1002/marc.200400065 